\title{
High throughput transformation of a Sorghum cDNA library for rice improvement
}

\author{
Kezhou Qin ${ }^{1} \cdot$ Ping Qiu ${ }^{1} \cdot$ Jianyu Wen ${ }^{1} \cdot$ \\ Yingguo $\mathrm{Zhu}^{1} \cdot$ Nengwu $\mathrm{Li}^{1} \cdot$ Shaoqing $\mathrm{Li}^{1}$
}

Received: 20 November 2015 / Accepted: 15 February 2016/Published online: 23 February 2016

(C) The Author(s) 2016. This article is published with open access at Springerlink.com

\begin{abstract}
The improvement of rice productivity is an important subject due to great population pressure. As plant functional genomics rapidly develops, increasing numbers of genes from different organisms are documented for rice improvement. Sorghum, a relative of rice, has many novel phenotypic characteristics such as strong stature, large panicle, drought tolerance, and a tolerance for low soil fertility, making this species an excellent gene resource for rice improvement. A Sorghum cDNA library was transformed into rice generating an overexpression population with 1153 fertile transgenic lines. Over 900 of these lines displayed phenotypic changes including: plant height, leaf shape and size, effective panicles, and other vegetative characteristics. Importantly, there were 19 lines with higher grain yield than the wild type, which demonstrates that the high-throughput transformation of overexpressing transgenes from Sorghum into rice is a highly efficient method for rice improvement.
\end{abstract}

Keywords cDNA library $\cdot$ Sorghum $\cdot$ Rice $\cdot$ Genetic improvement $\cdot$ Alien expression

Electronic supplementary material The online version of this article (doi:10.1007/s11240-016-0962-0) contains supplementary material, which is available to authorized users.

Shaoqing Li

shaoqingli@whu.edu.cn

1 State Key Laboratory of Hybrid Rice, Key Laboratory for Research and Utilization of Heterosis in Indica Rice of Ministry of Agriculture, Engineering Research Center for Plant Biotechnology and Germplasm Utilization of Ministry of Education, College of Life Sciences, Wuhan University, Wuhan 430072, China

\section{Introduction}

Rice is a staple crop, of which increases in yield by genetic improvement are of great significance for world food security, as it provides roughly $50 \%$ of the calories consumed by the world. In contrast to the swift expansion of the world's population, slow or stagnant rice yield increases would have profound implications for world food security (Ray et al. 2012). Rice improvement can be divided into two categories based on the gene resources: endogenous genes and alien genes. Increasing evidence has documented that alien genes from other plants can be employed for rice improvement. Previous reports show that a gene encoding the large subunit of AGPase as a ratelimiting enzyme in starch synthesis, maize shrunken-2, can increase rice yield by $23 \%$ (Hannah et al. 2012). Zmhdz10, a drought-induced HD-Zip I transcription factor overexpressed in both rice and Arabidopsis leads to enhanced drought and salt tolerance (Zhao et al. 2014). Transgenic rice plants overexpressing maize $\mathrm{C} 4$ рepc gene, which encodes phosphoenolpyruvate carboxylase (PEPC), enhance drought tolerance (Qian et al. 2015).

Sorghum, a Poaceae member related to sugar cane and maize, is the world's fifth most important cereal crop (Mall et al. 2011). A genetic analysis revealed that about onethird of the Sorghum genome is similar to rice in gene order and density (Paterson et al. 2009). Genetic variation in the partitioning of carbon into sugar stores versus cell wall mass, and in perenniality and associated features such as tillering and stalk reserve retention, make Sorghum an attractive system for the study of traits important in perennial cellulosic biomass crops. Drought tolerance and C4 photosynthesis, biochemical and morphological specializations, make Sorghum especially important in dry regions. These specializations increase net carbon 
assimilation at high temperatures, disease and insect resistance and high yield make an excellent gene resource for the genetic improvement of rice (Wang et al. 2013).

Recently, 27 overexpressing transgenes from Arabidopsis were examined in Arabidopsis that led to the identification of dominant estradiol-dependent stress tolerance genes (Papdi et al. 2008). Because of the efficacy and high-throughput of rice transformation, the improvement of rice using a Sorghum cDNA library would be practical and significant.

In the present study, we constructed a Sorghum overexpression cDNA library, and generated thousands of transgenes. Agronomic characteristics revealed that many transformants exhibited a change in phenotype, of which nineteen lines showed high yield by acquiring either more effective panicles, bigger seeds, or higher grain numbers per panicle than the wild type, implying that this method is effective and practically useful for rice improvement.

\section{Materials and methods}

\section{Plant materials}

Sorghum TX430 plants (Sorghum bicolor L.) from Professor Lijia Li's lab (Wuhan University, China) were grown in the greenhouse in Wuhan, Hubei province in China. Oryz. Sativa L. spp. Japonica, var 'Nipponbare' was used for transformation. T0 generation and T2 generation lines were planted in Wuhan and $\mathrm{T} 1$ generation were planted in Hainan in China.

\section{Sorghum cDNA expression library construction}

Total RNA $($ A260/A280 $=2.07$, total mass was $0.87 \mathrm{mg}$ ) was extracted from Sorghum bicolor (L.) young panicles about $8-12 \mathrm{~cm}$ before the heading stage using TRIzol reagent (Invitrogen, Carlsbad, CA). mRNA (A260/ $\mathrm{A} 280=2.23$, total mass is $2.87 \mu \mathrm{g}$ ) was isolated from the total RNA using the PolyATtract ${ }^{\circledR}$ mRNA Isolation System IV (without Magnetic Stand) Cat. \#Z5310 (Promega). A cDNA library was constructed by using CloneMiner ${ }^{\mathrm{TM}}$ II cDNA Library Construction Kit (Invitrogen, USA).

Gateway technology (Invitrogen, USA) contains two steps: BP recombination reaction (PCR fragment + entry vector) and $L R$ recombination reaction (entry vector after $B P$ recombination reaction + destination vector). After $L R$ recombination reaction, the cDNAs were recombined into overexpression vector $\mathrm{pH} 7 \mathrm{WG} 2 \mathrm{D}$ (Invitrogen, USA), and transformed using Agrobacterium-mediated transformation.

\section{Rice transformation}

Seed-embryos were induced to generate calli, which were then transformed based on the protocol (Hiei and Komari 2008) without heat treatment at $43{ }^{\circ} \mathrm{C}$ for $30 \mathrm{~min}$, and the calli only growed on N6 medium (Chu 1978) and MS medium (Murashige and Skoog 1962). Seeds were surface-sterilized with $75 \%$ ethanol for $1 \mathrm{~min}$ and $1.5 \% \mathrm{HgCl}_{2}$ for 10 min, washed with sterile $\mathrm{ddH}_{2} \mathrm{O}$, and cultured on $\mathrm{N}_{6}$ medium $\left(\mathrm{N}_{6}+2.5 \mathrm{mg} / \mathrm{L} 2,4-\mathrm{D}\right)$ for about 45 days and subcultured twice. The calli were harvested and precultured on preculture medium $\left(\mathrm{N}_{6}+20 \mathrm{mg} / \mathrm{L}\right.$ acetosyringone) for 3 days, then incubated for $15 \mathrm{~min}$ in Agrobacterium tumefaciens resuspended (OD600 $=0.1)$ in Agrobacterium suspension medium $\left(1 / 2 \mathrm{~N}_{6}+20 \mathrm{mg} / \mathrm{L}\right.$ acetosyringone + $10 \mathrm{~g} / \mathrm{L}$ Glucose). They were then dried on sterile filter paper and cocultivated with $A$. tumefaciens for 3 days at $21{ }^{\circ} \mathrm{C}$ on cocultivation medium (the same as preculture medium). After cocultivation, the rice calli were rinsed thoroughly (nine times) in sterile water containing $500 \mathrm{mg} / \mathrm{L}$ Cefotaxime Sodium Salt and transferred to selective medium $\left(\mathrm{N}_{6}+50 \mathrm{mg} / \mathrm{L}\right.$ hygromycin-B, $500 \mathrm{mg} / \mathrm{L}$ cefotaxime and $2.5 \mathrm{mg} / \mathrm{L} \mathrm{2,4-D)} \mathrm{for} 5$ weeks at $28^{\circ} \mathrm{C}$. Deep yellow calli were transferred to selection medium for 2 weeks, then vigorously growing calli were regenerated on regeneration medium (MS $+2 \mathrm{ml} / \mathrm{L} 6-\mathrm{BA}+2 \mathrm{ml} / \mathrm{L}$ kinetin $+0.2 \mathrm{ml} / \mathrm{L}$ IAA $+0.2 \mathrm{ml} / \mathrm{L} \mathrm{NAA}$ ) for 3 weeks at $28{ }^{\circ} \mathrm{C}$ under light. Seedlings from regeneration medium were transferred to rooting media (1/2 MS) for 2 weeks, then adapted to the external environment for 1 week, and then transferred to soil.

\section{Positive identification and expression analysis of transgenic lines}

Primers for hygromycin B resistance gene (HYP) (Supplementary Table 1) were designed for the identification of positive regeneration plantlets. The amplification program consisted of 10 min at $95{ }^{\circ} \mathrm{C}, 35$ cycles of $45 \mathrm{~s}$ at $95{ }^{\circ} \mathrm{C}, 45 \mathrm{~s}$ at $68{ }^{\circ} \mathrm{C}$ and $1 \mathrm{~min}$ at $72{ }^{\circ} \mathrm{C}$, followed by $10 \mathrm{~min}$ at $72{ }^{\circ} \mathrm{C}$.

For semi-quantitative RT-PCR, first-strand cDNA synthesis was performed with GoScript ${ }^{\mathrm{TM}}$ Reverse Transcription System (Promega, USA) using the total RNA extracted from young leaves. Semi-qPCR was performed with $1 \mu \mathrm{L}$ of template cDNA in a $20-\mu \mathrm{L}$ reaction system with Taq DNA Polymerase for $1 \mathrm{~min}$ at $94{ }^{\circ} \mathrm{C}$, followed by 36 cycles of $45 \mathrm{~s}$ at $94{ }^{\circ} \mathrm{C}, 45 \mathrm{~s}$ at $55^{\circ} \mathrm{C}$, and $1 \mathrm{~min}$ at $72{ }^{\circ} \mathrm{C}$. All semi-qPCR reactions were amplified using actin (AK061988) as internal control, and the PCR products were resolved by electrophoresis. The RT-PCR primers are listed in Supplementary Table 1. 


\section{Agronomic traits of 965 transgenic lines}

Plant height and effective panicles of five plants per line for 965 lines were tested, and A rice panicle which bears more than 5 grains was called as an effective panicle. Heading dates of six plants per line were also recorded. Three plants per line were randomly chosen to test flag leaf length and leaf width, and 3 flag leaves per plant were recorded.

\section{Agronomic traits of 93 transgenic lines}

Five plants per line for 93 lines were chosen to test seed setting rate, effective spike, grain number per plant, filled grain number per plant, grains per panicle, grain weight per unit area, and yield per plant.

\section{Tail-PCR}

According to the Tail-PCR method (Liu et al. 2005), we designed three specific primers: RB0B, RB1B and RB2B at the right border of the gateway vector pH7WG2D (Supplementary Table 1).

\section{Results}

\section{Construction of Sorghum bicolor (L.) cDNA overexpression library}

Alien introgressions provide a rich gene resource for crop improvement (Gill et al. 2011), and alien gene expression by transformation is a popular and practical approach to improve crop plants (Hu and Lubberstedt 2015). In order to improve rice using alien genes from other plants especially the grass family of C4 plants, a Sorghum cDNA library was constructed using the young inflorescences (about 8-12 cm length) of Sorghum. The titer of the destination cDNA library reached to $5.2 \times 10^{6} \mathrm{cfu}$ and the insert size ranged from
0.7-3.1 kb size (Fig. 1). Furthermore, we investigated the completeness of the cDNA orfs in the library, 37 clones were randomly selected and sequenced, of which, 36 clones had complete ORFs, and 20 were completely consistent with the full-length Sorghum cDNAs in NCBI (Supplementary Table 2). 10 novel genes were not present in the current NCBI database (Supplementary DNA sequences). These parameters suggest that the cDNA overexpression library was of high enough quality to be used for transformation.

\section{Generation of transgenic rice lines}

1518 independent transgenic lines were generated through Agrobacterium transformation and regeneration. Of which, 1153 positive lines were confirmed by PCR analysis (Figure S1) with a transformation efficiency of $76 \%$. In order to accurately evaluate the genetic effects of the transgenesis the copy number of the transgenes were investigated with genomic PCR (Ichikawa et al. 2006). Most lines harboured only one alien gene, the copy number of alien genes was about 1.26 on average in the 586 investigated transgenic lines (Fig. 2b). Furthermore, the completeness of the inserted cDNA in the transgenic lines was analyzed. In the 45 randomly selected transgenic lines, 42 cDNAs had complete ORFs, 21 cDNAs were consistent with the full-length cDNAs of Sorghum deposited in the NCBI database, and insertion sizes ranged from 437 to 2661 bp (Supplementary Table 3). RT-PCR analysis revealed that the alien genes were expressed in transgenic lines (Fig. 2a). These investigations suggest that the altered characteristics in the transformed rice lines were likely conferred by the inserted Sorghum genes.

\section{Observation on the agronomic traits of the transgenic lines}

To further evaluate the genetic effects of Sorghum cDNA inserted on rice development, the agricultural characteristics

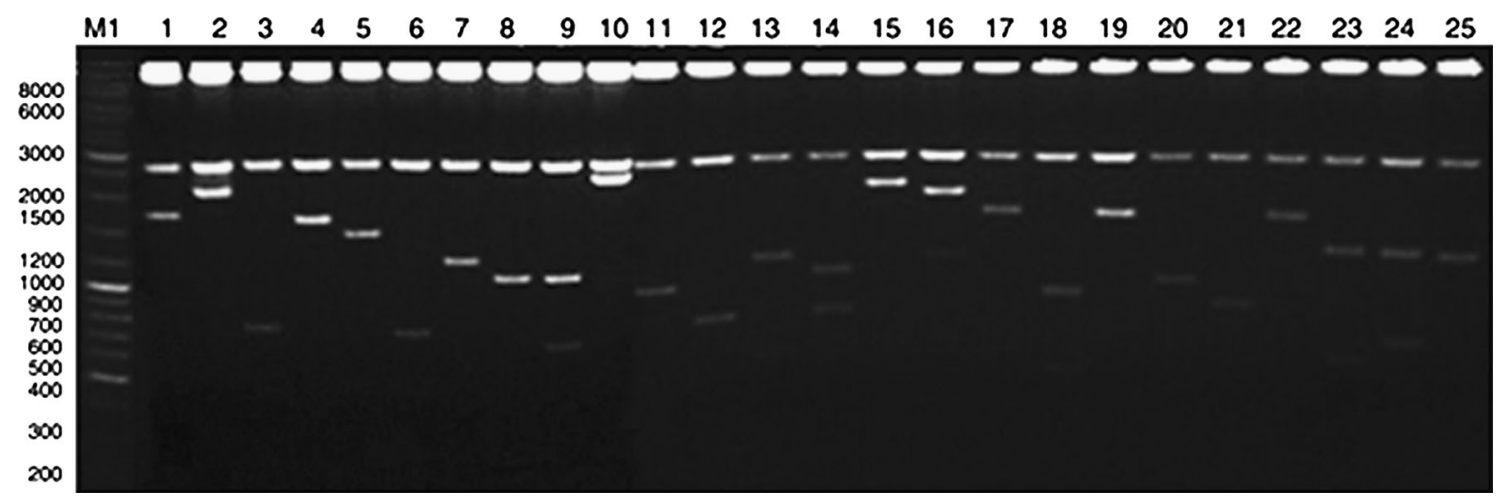

Fig. 1 Construction of Sorghum cDNA library. Recombined cDNA size in E. coli destination library was evaluated by restriction endonuclease BsrGI. M1 is $1 \mathrm{~kb}$ ladder 
Fig. 2 Molecular identification of the transgenic rice population. Note: a Expression analysis of Sorghum genes in the rice transgenic lines by semi-quantitative PCR. Actin was used as internal reference gene. $\mathbf{b}$ The copy number in transgenic rice lines

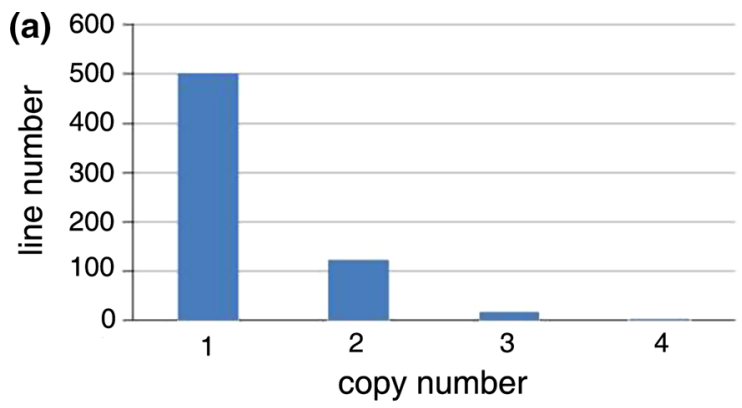

(b) 3-3 WT 11-3 WT 1-6 WT 3-9 WT 2-6 WT 2-9 WT 11-7 WT 5-9 WT 1-4 WT 2-1 WT

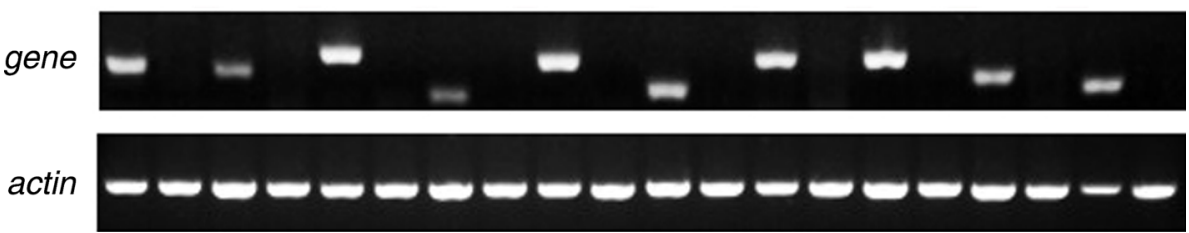

of transgenic lines were investigated carefully. The 965 fertile transgenic lines were tested based on the agronomical traits including effective panicle, plant height, leaf length, leaf width, and heading date (Fig. 3), although some plants exhibited changes in multiple traits.

890 lines had longer leaves, and 563 lines showed wider or narrower leaves compared to the wild type. For heading date, 300 lines were delayed, while 169 lines were earlier than the wild type. 9 lines were taller, and 874 lines were shorter than the wild type. For the effective panicle, 807 lines were increased, and only three lines were lower than the wild type. These data suggest that the phenotype of gross morphology were changed in over $92 \%$ percent of the transgenic lines (Table 1), which means that overexpression of Sorghum cDNA in rice caused a great morphology variation.
Fig. 3 Phenotype categorization of transgenic lines. a Leaf color; b Plant height; c Panicle architecture; d Effective panicle, e Leaf shape, scale bar $=7.33 \mathrm{~cm}$. f Grain length, scale bar $=0.38 \mathrm{~cm}$. g Grain width, scale bar $=0.40 \mathrm{~cm}$
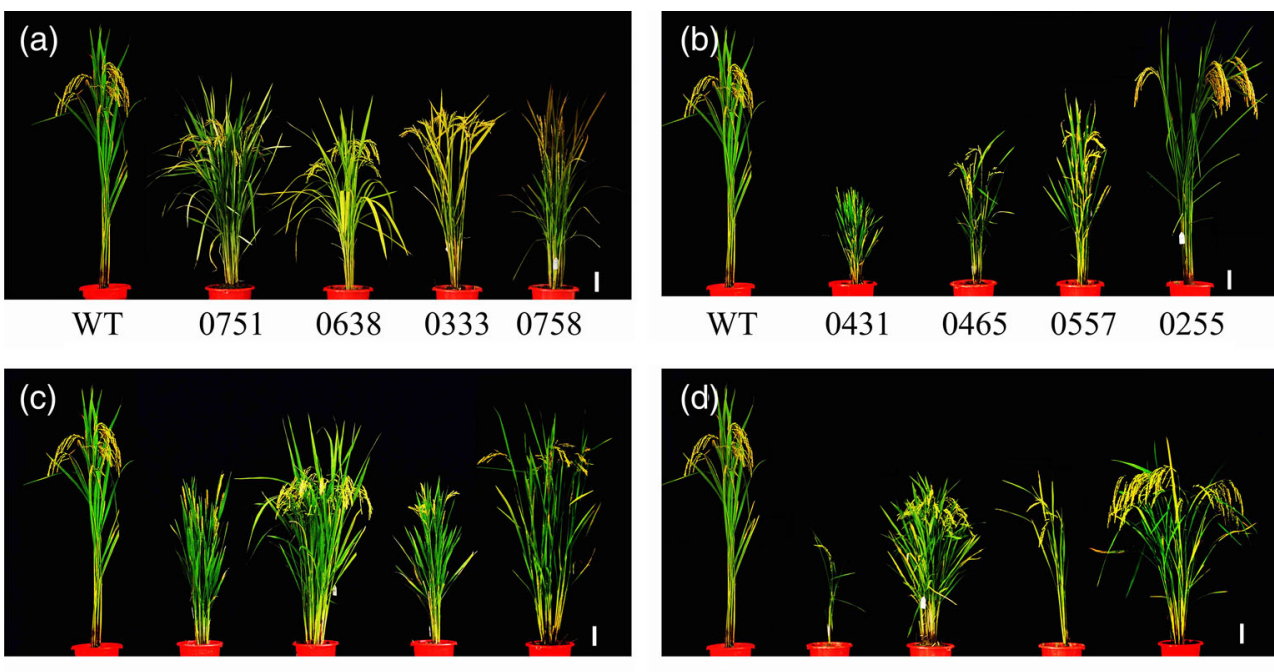

$\begin{array}{lllll}\text { WT } & 0752 & 0568 & 0262 & 0837\end{array}$

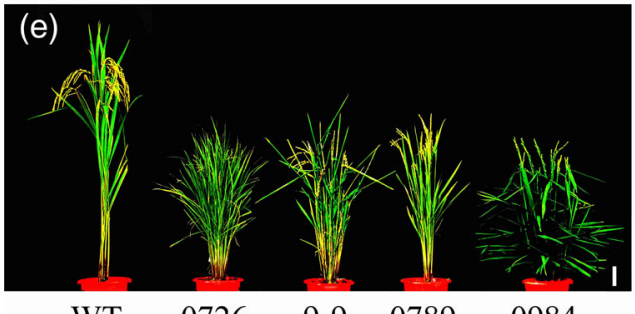

(f)

(g)

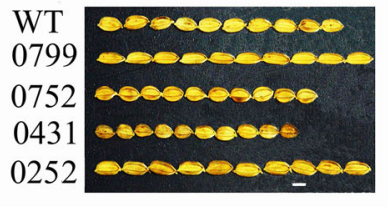

WT councion 0799 curvuruts 0752 occoworcos 0431 cescecesces 0252 colcunurs 


\section{Characterization of the high yield transgenic lines}

Grain yield is the most important characteristic for rice improvement, and is a great focus for breeders around the world. In the present study, we investigated lines with obvious yield improvements, and yield-related traits such as effective panicles, grain size and grain number. In total, 93 lines were selected and were investigated further in four yield-determined traits containing seed setting rate, effective panicle, 1000-grain weight and grain number per panicle. Of these lines yield was increased in 19 lines relative to the wildtype (Table 2), 29 lines had reduced yield, and another 45 lines lacked an apparent change (Supplementary Table 4).

When we investigated the 19 yield-increased lines, effective panicles significantly increased in 18 lines (from 11.33 to 21.67 ) compared to the wildtype (7.67). 9 lines increased 1000-grain weight from (24.69 to $27.65 \mathrm{~g}$ ) than in the wild type $(23.72 \mathrm{~g})$. One line had increased grain number (155.04) than the wild type (89.39). Then, we analyzed the insert fragments of the 19 high yield transgenic lines to explore the potential function of these genes in plants. 14 genes were separately cloned from 14 high yield transgenic lines, and sequence analysis showed that CDSs (coding sequence) of 13 genes were completely consistent with genes in the NCBI database, with the exception of line 0402 , which had a $170 \mathrm{bp}$ deletion at the $5^{\prime}$ end of the CDS (Supplementary Table 5).

\section{Genetic validation of phenotypes in transgenic lines}

We investigated a possible mutation in transgenic line 0752, which exhibited dwarf plants, smaller grains, dense and erect panicles (Fig. 4). Tail-PCR showed that the insert gene Sb01g013740 was located at 7523486 bp on chromosome 3, which is $4.4 \mathrm{~kb}$ upstream of the 0 s03 $\mathrm{g} 0242300$ (LOC_Os03g13870.1, 1386 bp), and did not affect other genes. Sb01g013740 encodes a patatin-like phospholipase domain containing protein (Marchler-Bauer et al. 2015) which is similar to DEP3 in rice. Phenotypic analysis showed that a rice $\operatorname{dep} 3$ mutant with a deletion in the last $47 \mathrm{bp}$ of the third exon exhibited a very similar phenotype to line 0752 , with the exception of plant height (Qiao et al. 2011). This implies that Sb01g013740 in Sorghum may have the same function as DEP3 in rice. Furthermore, we transformed the $S b 01 g 013740$ into rice again to confirm the phenotype. The positive $T_{0}$ transgene rice lines were tested with PCR (Figure S2), and demonstrated a similar phenotype to the 0752 line, with the exception of lacking dense and erect panicles (Fig. 4 and Supplementary Table 6). This discrepancy could be because the $T_{0}$ generation transgenic lines might be too weak to keep the panicles erect or perhaps the transgenic lines were not homozygous.

\section{Discussion}

Our experimental results are very successful, and the reason can be from the following two aspects. First, It is feasible to use gateway technology to build the cDNA overexpression library, $50 \%$ of full-length cDNAs of 82 $(37+45)$ cDNAs in our library were between $43 \%$ of 14 cDNAs (LeClere and Bartel 2001) and $60 \%$ of 27 cDNAs (Papdi et al. 2008), so the data was more convincing; considering the high GC content of cDNAs in Sorghum, we thought it was not easy to get cDNAs of such a high integrity; in addition, when we done homologous gene alignment we found 10 new genes and new gene ratio was as high as $10 /(37+45+14)$. Second, the method of cDNA overexpression library had its own advantages compared with activation-tagged method, FOX-hunting system (Full-length cDNA Over2-eXpressing gene hunting system) and BIBAC (Binary Bacterial artificial chromosome). Using the activation-tagged method, it may be not easy to analyse gene-phenotype relationship, because multiple genes at a distance of as much as $10.7 \mathrm{~kb}$ from the insertion site could be activated simultaneously (Jeong et al. 2006). FOX-hunting system was first built in Arabidopsis (Ichikawa et al. 2006), but the collection of fulllength cDNAs is time-consuming and needs a huge amount

Table 1 Categories of the 965 transgenic lines based on agronomic traits

\begin{tabular}{llllll}
\hline Lines & \multicolumn{2}{l}{ Characters } \\
\cline { 2 - 6 } & Leaf length $(\mathrm{cm})$ & Leaf width $(\mathrm{cm})$ & Heading date $(\mathrm{d})$ & Plant height $(\mathrm{cm})$ & Effective panicles \\
\hline WT & $38.0 \pm 2.7$ & $1.54 \pm 0.1$ & $74 \pm 0.8$ & $96.8 \pm 0.7$ & $7.7 \pm 0.6$ \\
Transgenic lines & $10.9 \sim 35.3$ & $0.7 \sim 1.7$ & $68 \sim 88.0$ & $22.5 \sim 110.5$ & $2.7 \sim 44.0$ \\
Number of altered phenotype plants & 890 & 563 & 469 & 883 & 810 \\
Ration to the total $(\%)$ & 92.2 & 58.3 & 48.6 & 91.5 & 83.9 \\
\hline
\end{tabular}

Leaf means flag leaf 
Table 2 Agronomic traits of 19 higher grain yield transgenic lines

\begin{tabular}{|c|c|c|c|c|c|}
\hline Sample number & Grain yield $(\mathrm{g})$ & Seed setting rate $(\%)$ & Effective panicle & 1000 -grain weight $(\mathrm{g})$ & Grain number per panicle \\
\hline WT & $14.92 \pm 2.05$ & $0.92 \pm 0.01$ & $7.67 \pm 0.58$ & $23.72 \pm 0.42$ & $89.39 \pm 14.09$ \\
\hline 0001 & $27.67 \pm 7.52 * *$ & $0.9 \pm 0.02$ & $13.33 \pm 3.06^{* *}$ & $25.12 \pm 0.62 * *$ & $91.37 \pm 10.4$ \\
\hline 0067 & $25.19 \pm 2.12 * * *$ & $0.81 \pm 0.02 * * *$ & $15.33 \pm 0.58 * * *$ & $25.4 \pm 0.53 * *$ & $79.76 \pm 2.52$ \\
\hline 0093 & $22.87 \pm 2.67 * *$ & $0.78 \pm 0.07$ & $11.67 \pm 1.15^{* * *}$ & $26.93 \pm 0.98 * * *$ & $94.23 \pm 14.96$ \\
\hline 0212 & $21.8 \pm 2.86^{* *}$ & $0.82 \pm 0.05^{* *}$ & $13.33 \pm 0.58 * * *$ & $27.65 \pm 2.25^{* *}$ & $72.69 \pm 10.72$ \\
\hline 0231 & $28.82 \pm 3.16^{* * *}$ & $0.79 \pm 0.03 * * *$ & $14 \pm 1.73 * * *$ & $24.76 \pm 0.62$ & $105.23 \pm 8.89$ \\
\hline 0255 & $27.66 \pm 6.74 * *$ & $0.79 \pm 0.09$ & $9.67 \pm 2.52$ & $23.6 \pm 0.16$ & $155.04 \pm 16.94 * * *$ \\
\hline 0266 & $29.65 \pm 4.8^{* * *}$ & $0.9 \pm 0.02$ & $14.33 \pm 2.08 * * *$ & $25.53 \pm 0.92 * *$ & $89.8 \pm 7.59$ \\
\hline 0274 & $35.74 \pm 4.85^{* * *}$ & $0.88 \pm 0.02 * *$ & $21.67 \pm 2.08 * * *$ & $24.63 \pm 0.58$ & $76.26 \pm 3.96$ \\
\hline 0294 & $31.19 \pm 8.19^{* *}$ & $0.87 \pm 0.04$ & $19.67 \pm 3.51 * * *$ & $24.75 \pm 1.02$ & $73.33 \pm 6.05$ \\
\hline 0340 & $24.6 \pm 2.34 * * *$ & $0.79 \pm 0.04 * * *$ & $17 \pm 1.73 * * *$ & $23.33 \pm 0.73$ & $78.94 \pm 9.24$ \\
\hline 0402 & $21.92 \pm 1.45^{* * *}$ & $0.86 \pm 0.03 * *$ & $12.67 \pm 1.53 * * *$ & $23.99 \pm 0.86$ & $84.79 \pm 11.5$ \\
\hline 0509 & $25.47 \pm 1.9^{* * *}$ & $0.76 \pm 0.09$ & $15.33 \pm 2.52 * * *$ & $24.99 \pm 0.55^{* *}$ & $88.44 \pm 3.04$ \\
\hline 0572 & $23.2 \pm 3.62 * *$ & $0.83 \pm 0.01 * * *$ & $16.67 \pm 3.06^{* * *}$ & $20.88 \pm 0.25 * * *$ & $80.52 \pm 3.08$ \\
\hline 0711 & $19.32 \pm 1.05^{* *}$ & $0.83 \pm 0.02 * * *$ & $11.33 \pm 0.58 * * *$ & $26.52 \pm 0.78 * * *$ & $77.77 \pm 1.91$ \\
\hline 0762 & $23.59 \pm 2.74 * *$ & $0.87 \pm 0.09$ & $16.67 \pm 1.53 * * *$ & $24.17 \pm 1.28$ & $67.7 \pm 6.58$ \\
\hline 0808 & $28.01 \pm 3.31 * * *$ & $0.81 \pm 0.01 * * *$ & $16.33 \pm 1.53 * * *$ & $26.41 \pm 0.41 * * *$ & $80.46 \pm 9.18$ \\
\hline 0815 & $24.84 \pm 1.69 * * *$ & $0.82 \pm 0.02 * * *$ & $18.33 \pm 2.08 * * *$ & $24.69 \pm 0.14 * *$ & $67.06 \pm 3.3$ \\
\hline 0864 & $33.55 \pm 6.75^{* *}$ & $0.9 \pm 0.01 * *$ & $15.67 \pm 2.52 * * *$ & $24.93 \pm 0.66$ & $95.76 \pm 9.05$ \\
\hline 0887 & $28.89 \pm 2.72 * * *$ & $0.87 \pm 0.04$ & $14.33 \pm 2.08 * * *$ & $23.69 \pm 0.37$ & $98.99 \pm 9.58$ \\
\hline
\end{tabular}

WT wild type

** and *** mean significant difference at 0.05 and 0.01 level, respectively

Fig. 4 Retransformation verification of Sb01g013740 from the 0752 line. a Gross phenotype of WT and transgene line L1, scale bar $=7.33 \mathrm{~cm}$. b Panicles of WT, 0752 line and the retransformed lines of L1, $\mathrm{L} 2$ and L3, scale bar $=0.94 \mathrm{~cm}$. c Grain size of WT, 0752 line and the retransformed lines of L1, L2 and $\mathrm{L} 3$, scale bar $=0.26 \mathrm{~cm}$ (a)

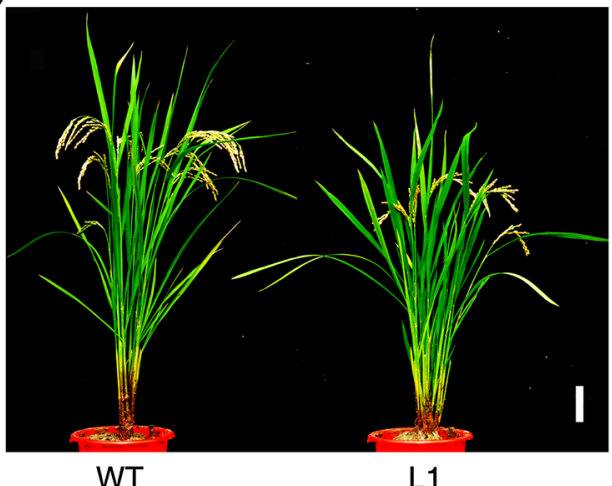

(c)

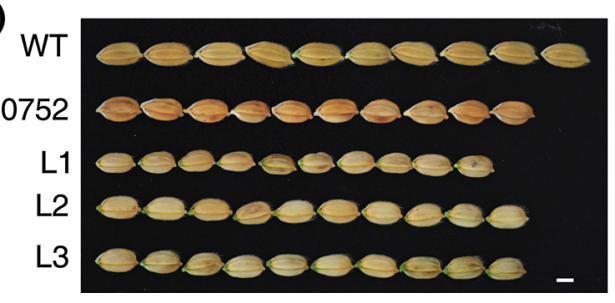

(b)

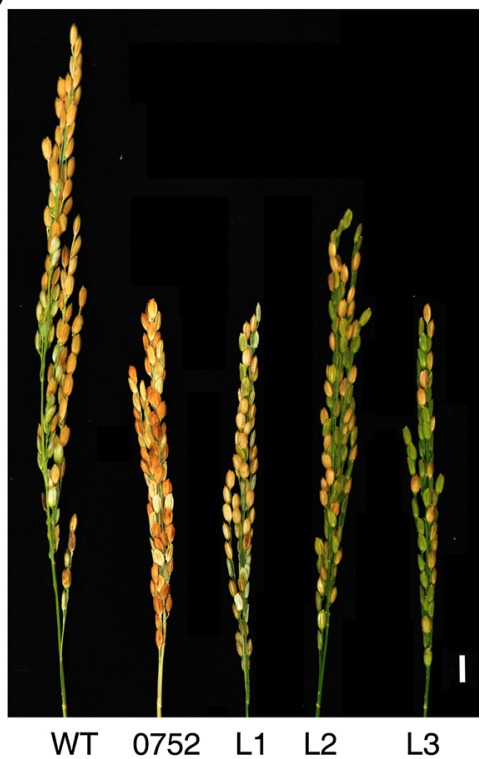

of work in genome-wide (Kondou et al. 2010) and requires prior knowledge of genome sequences and gene annotations; and to our knowledge, this system only utilized full
length-cDNAs of both rice and Arabidopsis which were collected by FAIS and RIKEN(Hakata et al. 2010; Ichikawa et al. 2006). BIBAC (Wang et al. 2015) has a 
transgenic bottleneck, which has not been broken to massively transform large DNA fragments into another species, and analysis of subsequent gene function is difficult, too.

Heterologous expression of alien genes has been a practical an effective approach for engineering improvements into crop plants (Pratap and Kumar 2014). Usually plant genes that confer an important function are employed to improve the same agricultural character in related crop plants (Datta et al. 2012; Jacobs et al. 2011; Li et al. 2012; Oliva et al. 2014; Pasquali et al. 2008; Shin et al. 2006; Zhao et al. 2015; Zheng et al. 2015). Unfortunately, It is inefficient to improve rice by transforming one gene at a time, but high-throughput overexpression of cDNA libraries from other plants can surpass this limitation, because foreknowledge of gene function is unnecessary. In our research, over $90 \%$ of transgenic lines altered an agricultural trait, which shows that alien expression of Sorghum cDNA can greatly affect plant phenotype, although correlating genes with function requires further study.

We believe that the high yield of 19 strains were caused by the overexpression of these genes. The majority of copy number was single copy by genomic PCR, combined with the identification results of semi-quantitative RT-PCR, the expressed genes showed the dominant effect; the redundancy and repeated genes of rice accounted for $29 \%$ (International Rice Genome Sequencing 2005), that is to say, loss of function genes in the insertion site may not result in phenotype change. In this research, 19 plants exhibited a higher grain yield than the wild type, of which, 16 lines increased over $50 \%$ mainly as a result of increasing effective panicles (Table 1). Interestingly, of the 14 Sorghum genes identified from the high grain yield plants, seven genes have proposed functions related to stress response through homologous analysis (Table 2). Of which, XM_002452726.1 from the line 0067, a homologue of Zea mays dhn2 (Campbell et al. 1998), is a member of dehydrin family and is related to drought tolerance. XM_008661925.1 from the line 0815, is homologous to ERD15 (EARLY RESPONSIVE TO DEHYDRATION 15) in Zea mays, and is related to ABA response and stress tolerance in Arabidopsis thaliana (Aalto et al. 2012). $X M \_002452812.1$ from the line 0887 is homologous to ascorbate-specific transmembrane electron transporter 1 (Cytochrome b561-1) in Zea mays, and to cytochrome b561 proteins, which play an important role in plant growth, development, and the prevention of damage to plants (Opiyo and Moriyama 2010). Manipulation of cytochrome b6/f complex can potentially improve grain yield (Yamori et al. 2015). As reported in an article, the yield increase is thus achieved by increasing the ability of stress (Mao et al. 2015). Considering that Sorghum has a strong adaptability to the environment, these analyses imply that Sorghum genes related to drought tolerance, salt tolerance, cytochrome, dehydrin, high temperature tolerance, disease and insect resistance can functionally enhance rice yield. This reveals that some evolutionarily homologous genes may show different functions when alien genes were expressed in different plant species (Gururani et al. 2015; Hong et al. 2014), and provide a novel approach to explore gene resources for plant improvement.

Retransformation was necessary, because the phenotype is not only from the transgene itself but also other factors such as gene disruption at the insertion site, and the mutation during tissue culture. Phenotypes caused by culture mutations in both rice and Arabidopsis transformation is $5-10 \%$ (Larmande et al. 2008). So a careful comprehensive analysis of each mutant line is necessary to ensure a connection between a transgene and phenotype (Nishimura et al. 2006). In view of this situation, we put forward an idea which was introducing Ac/Ds transposon elements into overexpression transgenic vector and then the vectors were transformed into rice, similar to large-scale Ac/Ds transposon T-DNA insertion mutant library built by China National Rice Research Institute. At last, we mainly study effect of the transgene, analyse the phenotype of the transgenic progeny population for determining the relation between gene and phenotype, eliminating the need for transgenic tedious steps (especially when indica rice is not suitable to create large-scale mutant library).

Acknowledgments This research was partly supported by the National Transgenic Research and Development Program (2014ZX08001-004) and the 863 Program (2012AA10A303) of China, and the Key Grant Project of Chinese Ministry of Education (Grant No. 313039).

Open Access This article is distributed under the terms of the Creative Commons Attribution 4.0 International License (http://crea tivecommons.org/licenses/by/4.0/), which permits unrestricted use, distribution, and reproduction in any medium, provided you give appropriate credit to the original author(s) and the source, provide a link to the Creative Commons license, and indicate if changes were made.

\section{References}

Aalto MK et al (2012) ERD15-an attenuator of plant ABA responses and stomatal aperture. Plant Sci 182:19-28. doi:10.1016/j. plantsci.2011.08.009

Campbell SA, Crone DE, Ceccardi TL, Close TJ (1998) A ca. 40 kDa maize (Zea mays L.) embryo dehydrin is encoded by the dhn2 locus on chromosome 9. Plant Mol Biol 38:417-423

Chu CC (1978) The N6 medium and its applications to anther culture of cereal crops. In: Proceedings of symposium on plant tissue culture pp. $43-50$

Datta K, Baisakh N, Ganguly M, Krishnan S, Yamaguchi Shinozaki K, Datta SK (2012) Overexpression of Arabidopsis and rice stress genes' inducible transcription factor confers drought and salinity tolerance to rice. Plant Biotechnol J 10:579-586. doi:10. 1111/j.1467-7652.2012.00688.x 
Gill BS, Friebe BR, White FF (2011) Alien introgressions represent a rich source of genes for crop improvement. Proc Natl Acad Sci USA 108:7657-7658. doi:10.1073/pnas.1104845108

Gururani MA, Ganesan M, Song PS (2015) Photo-biotechnology as a tool to improve agronomic traits in crops. Biotechnol Adv 33:53-63. doi:10.1016/j.biotechadv.2014.12.005

Hakata $M$ et al (2010) Production and characterization of a large population of cDNA-overexpressing transgenic rice plants using Gateway-based full-length cDNA expression libraries. Breed Sci 60:575-585. doi:10.1270/jsbbs.60.575

Hannah LC et al (2012) A shrunken-2 transgene increases maize yield by acting in maternal tissues to increase the frequency of seed development. Plant Cell 24:2352-2363. doi:10.1105/tpc.112. 100602

Hiei Y, Komari T (2008) Agrobacterium-mediated transformation of rice using immature embryos or calli induced from mature seed. Nat Protoc 3:824-834. doi:10.1038/nprot.2008.46

Hong Y et al (2014) Transcript suppression of TaGW2 increased grain width and weight in bread wheat. Funct Integr Genomics 14:341-349. doi:10.1007/s10142-014-0380-5

$\mathrm{Hu}$ S, Lubberstedt $\mathrm{T}$ (2015) Getting the 'MOST' out of crop improvement. Trends Plant Sci 20:372-379. doi:10.1016/j. tplants.2015.03.002

Ichikawa T et al (2006) The FOX hunting system: an alternative gainof-function gene hunting technique. Plant J 48:974-985. doi:10. 1111/j.1365-313X.2006.02924.x

International Rice Genome Sequencing P (2005) The map-based sequence of the rice genome. Nature 436:793-800. doi:10.1038/ nature 03895

Jacobs A, Ford K, Kretschmer J, Tester M (2011) Rice plants expressing the moss sodium pumping ATPase PpENA1 maintain greater biomass production under salt stress. Plant Biotechnol J 9:838-847. doi:10.1111/j.1467-7652.2011.00594.x

Jeong DH et al (2006) Generation of a flanking sequence-tag database for activation-tagging lines in japonica rice. Plant J 45:123-132. doi:10.1111/j.1365-313X.2005.02610.x

Kondou Y, Higuchi M, Matsui M (2010) High-throughput characterization of plant gene functions by using gain-of-function technology. Annu Rev Plant Biol 61:373-393. doi:10.1146/ annurev-arplant-042809-112143

Larmande P et al (2008) Oryza Tag Line, a phenotypic mutant database for the Genoplante rice insertion line library. Nucleic Acids Res 36:D1022-D1027. doi:10.1093/nar/gkm762

LeClere S, Bartel B (2001) A library of Arabidopsis 35S-cDNA lines for identifying novel mutants. Plant Mol Biol 46:695-703. doi:10.1023/a:1011699722052

Li W et al (2012) Ectopic expression of Hrf1 enhances bacterial resistance via regulation of diterpene phytoalexins, silicon and reactive oxygen species burst in rice. PLoS ONE 7:e43914. doi:10.1371/journal.pone.0043914

Liu YG, Chen Y, Zhang Q (2005) Amplification of genomic sequences flanking T-DNA insertions by thermal asymmetric interlaced polymerase chain reaction. Methods Mol Biol 286:341-348

Mall TK et al (2011) Expression of the rice CDPK-7 in sorghum: molecular and phenotypic analyses. Plant Mol Biol 75:467-479. doi:10.1007/s11103-011-9741-9

Mao $\mathrm{H}$ et al (2015) A transposable element in a NAC gene is associated with drought tolerance in maize seedlings. Nature Commun 6:8326. doi:10.1038/ncomms9326

Marchler-Bauer A et al (2015) CDD: NCBI's conserved domain database. Nucleic Acids Res 43:D222-D226. doi:10.1093/nar/ gku1221
Murashige T, Skoog F (1962) A revised medium for rapid growth and bio assays with tobacco tissue cultures. Physiol Plant 15:473-497

Nishimura A, Aichi I, Matsuoka M (2006) A protocol for Agrobacterium-mediated transformation in rice. Nat Protoc 1:2796-2802. doi:10.1038/nprot.2006.469

Oliva N et al (2014) Large-scale production and evaluation of markerfree rice IR64 expressing phytoferritin genes. Mol Breeding 33:23-37. doi:10.1007/s11032-013-9931-z

Opiyo SO, Moriyama EN (2010) Mining Cytochrome b561 proteins from plant genomes. Int J Bioinform Res Appl 6:209-221. doi:10.1504/ijbra.2010.032122

Papdi C, Abraham E, Joseph MP, Popescu C, Koncz C, Szabados L (2008) Functional identification of Arabidopsis stress regulatory genes using the controlled cDNA overexpression system. Plant Physiol 147:528-542. doi:10.1104/pp.108.116897

Pasquali G, Biricolti S, Locatelli F, Baldoni E, Mattana M (2008) Osmyb4 expression improves adaptive responses to drought and cold stress in transgenic apples. Plant Cell Rep 27:1677-1686. doi:10.1007/s00299-008-0587-9

Paterson AH et al (2009) The Sorghum bicolor genome and the diversification of grasses. Nature 457:551-556. doi:10.1038/ nature 07723

Pratap A, Kumar J (2014) Alien gene transfer in crop plants volume 2: achievements and impacts. Springer, New York

Qian B, Li X, Liu X, Chen P, Ren C, Dai C (2015) Enhanced drought tolerance in transgenic rice over-expressing of maize $\mathrm{C} 4$ phosphoenolpyruvate carboxylase gene via $\mathrm{NO}$ and $\mathrm{Ca}(2+)$. J Plant Physiol 175:9-20. doi:10.1016/j.jplph.2014.09.019

Qiao Y et al (2011) Fine mapping and candidate gene analysis of dense and erect panicle 3, DEP3, which confers high grain yield in rice (Oryza sativa L.). Theor Appl Genet 122:1439-1449. doi:10.1007/s00122-011-1543-6

Ray DK, Ramankutty N, Mueller ND, West PC, Foley JA (2012) Recent patterns of crop yield growth and stagnation. Nat Commun 3:1293. doi: $10.1038 /$ ncomms 2296

Shin YM, Park HJ, Yim SD, Baek NI, Lee CH, An G, Woo YM (2006) Transgenic rice lines expressing maize $\mathrm{C} 1$ and R-S regulatory genes produce various flavonoids in the endosperm. Plant Biotechnol J 4:303-315. doi:10.1111/j.1467-7652.2006. 00182.x

Wang YH, Acharya A, Burrell AM, Klein RR, Klein PE, Hasenstein KH (2013) Mapping and candidate genes associated with saccharification yield in sorghum. Genome 56:659-665. doi:10. 1139/gen-2013-0134

Wang Y et al (2015) Transformation of rice with large maize genomic DNA fragments containing high content repetitive sequences. Plant Cell Rep. doi:10.1007/s00299-015-1764-2

Yamori W, Kondo E, Sugiura D, Terashima I, Suzuki Y, Makino A (2015) Enhanced leaf photosynthesis as a target to increase grain yield: insights from transgenic rice lines with variable Rieske FeS protein content in the Cytochrome b6/f complex. Plant Cell Environ. doi:10.1111/pce.12594

Zhao Y et al (2014) A novel maize homeodomain-leucine zipper (HD-Zip) I gene, Zmhdz10, positively regulates drought and salt tolerance in both rice and Arabidopsis. Plant Cell Physiol 55:1142-1156. doi:10.1093/pcp/pcu054

Zhao X, Xu M, Wei R, Liu Y (2015) Expression of OsCAS (CalciumSensing Receptor) in an Arabidopsis mutant increases drought tolerance. PLoS one 10:e0131272. doi:10.1371/journal.pone. 0131272

Zheng S et al (2015) Evaluating the effect of expressing a peanut resveratrol Synthase Gene in Rice. PloS one 10:e0136013. doi:10.1371/journal.pone. 0136013 